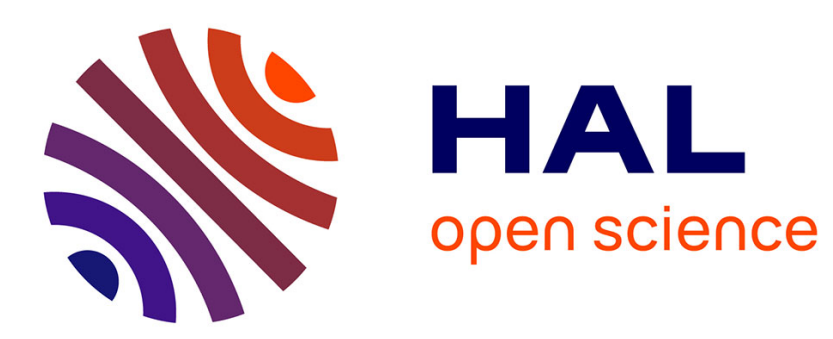

\title{
SOA-based devices for all-optical signal processing
}

B Dagens, A Labrousse, R Brenot, B Lavigne, M Renaud

\section{To cite this version:}

B Dagens, A Labrousse, R Brenot, B Lavigne, M Renaud. SOA-based devices for all-optical signal processing. Optical Fiber Communication Conference 2003, Mar 2003, Atlanta, United States. paper ThX1, 10.1109/OFC.2003.316006 . hal-03331042

\section{HAL Id: hal-03331042 \\ https://hal.science/hal-03331042}

Submitted on 1 Sep 2021

HAL is a multi-disciplinary open access archive for the deposit and dissemination of scientific research documents, whether they are published or not. The documents may come from teaching and research institutions in France or abroad, or from public or private research centers.
L'archive ouverte pluridisciplinaire HAL, est destinée au dépôt et à la diffusion de documents scientifiques de niveau recherche, publiés ou non, émanant des établissements d'enseignement et de recherche français ou étrangers, des laboratoires publics ou privés. 


\title{
SOA-based devices for all-optical signal processing
}

\author{
B. Dagens, A. Labrousse, R. Brenot, B. Lavigne, M. Renaud \\ Alcatel Research \& Innovation, Route de Nozay, F91460 Marcoussis, France \\ Phone: 331696312 35.Fax: 331696318 13.Email: beatrice.dagens@alcatel.fr
}

\begin{abstract}
Fast all-optical signal processing functions realized with non-linear semiconductor optical amplifiers, particularly those associated to interferometric structures, are presented. Different integration schemes are compared with criteria concerning device insertion in systems. (C)2003 Optical Society of America OCIS codes: (000.0000) General
\end{abstract}

\section{Introduction}

Development of all-optical and wavelength domain multiplexing (WDM) networks requires numerous and diversified optical processing functions like wavelength conversion, regeneration, add\&drop, time domain multiplexing or logic functions. A fast non-linear element is necessary to realize such functions. The SOA (Semiconductor Optical Amplifier) is a particularly good candidate thanks to its compactness, its low consuming operation, its thermal stability and its non-linear properties : with reasonably moderate input optical and electrical powers, SOA can induce interaction between signals thanks to FWM (Four Wave Mixing), XGM (Cross Gain Modulation), or XPM (Cross Phase Modulation) [1,2]. FWM is intrinsically fast and can simultaneously act on several WDM channels, but requires a quite complex pumping scheme to ensure polarization independence and a large wavelength span operation. The XGM scheme can be polarization independent, operate on a wide wavelength span and have a large input power dynamic range (IPDR). Anyway, because of a strong induced chirp and a low output extinction ratio, the cross-gain modulated signal needs to be corrected before a transmission or a cascade, for example thanks to a fiber Bragg grating [3]. Finally, the XPM is usually used with an interferometric structure in order to extract an amplitude modulated signal. For this reason, XPM devices present the highest non-linearity degree, made not only of the non-linear SOA but also of the non-linear interferometer : this makes very functional and flexible structures with the particularity to be able to re-distribute the noise and thus to regenerate the signals.

In this context we will focus on SOA-based interferometric devices. The principles and the achievable functions with such structures will be first presented, with a particular interest for regenerative devices. Then, we will present different SOA-based interferometer integration schemes and their capability for an easy insertion in real systems.

\section{SOA-based interferometers: principles and functions}

The particularity of the SOA-based devices using an interference scheme is their capacity to regenerate the signals thanks to their sinusoidal transfer function. In these devices, the regeneration is often based on wavelength conversion. In these cases, an optical clock can be introduced and become the converted signal to realize complete (3R) signal regeneration (Reamplifying, Reshaping, Retiming). In the semiconductor ultrafast nonlinear interferometer (UNI) [4], the probe signal (clock signal) is split into two orthogonally polarized pulses, which are separated by several picosecond (typically twice the data pulse width and lower than the bit duration) before to go through a SOA whose gain and index are modulated by the data signal. The delay between both probe pulses is then reversed and the two components recombined before passing through a polarizer. Cascaded $40 \mathrm{~Gb} / \mathrm{s} 3 \mathrm{R}$ data regeneration has been shown with this device, demonstrating $2000 \mathrm{~km}$ transmission in a recirculating loop with 100 $\mathrm{km}$ spaced regenerators. In a quite different scheme, the DISC (delayed-interference signal-wavelength converter) [5], and, in integrated configuration, the SOA-DI (SOA with delayed interference) [6] are made of an SOA followed by an asymmetric two branches interferometer: the converted signal (probe) is phase modulated in the SOA and goes through the interferometer which extracts the amplitude modulation. The carrier induced relaxation time of the SOA is masked thanks to the temporal delay between the two interferometer branches and the tunable phase shift. Such structures have been implemented with a clock as the probe signal for $3 \mathrm{R}$ regeneration at $84 \mathrm{~Gb} / \mathrm{s}$ [5] and $40 \mathrm{~Gb} / \mathrm{s}$ [6] but with cascadability issue still to be demonstrated. In a third configuration, 3R optical regeneration was successfully demonstrated at $40 \mathrm{~Gb} / \mathrm{s}$ with monolithically integrated SOA-based Mach-Zehnder interferometers (SOA-MZI) used in differential mode : the basic layout of this regenerator, made of two interferometers, is shown in Figure 1(a). In each SOA-MZI, the conversion SOA's are directly placed in the interferometer arms. The 3R regeneration is realized thanks to the interferometers high non-linearity, the conversion to the clock and the amplification. A penalty-free cascade of more than 100 regenerators has been obtained as shown in Figure 1(b) [7]. 
(a)

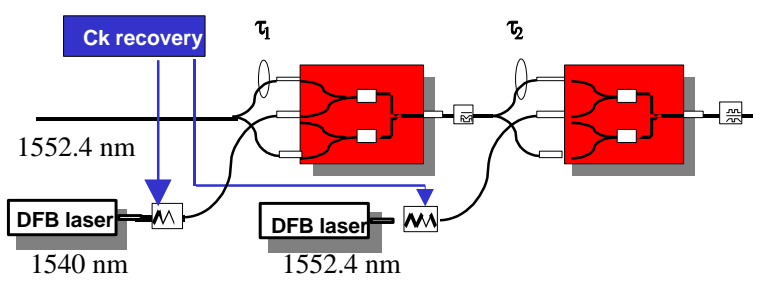

(b)

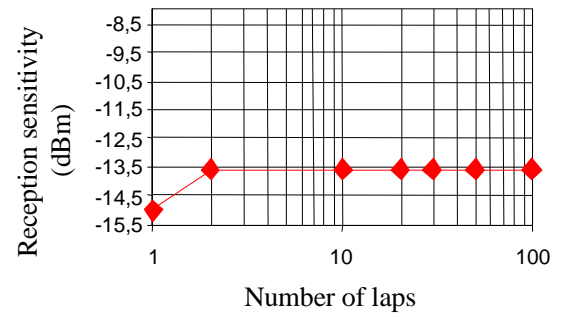

Fig. 1.SOA-MZI based optical 3R regenerator for $40 \mathrm{~Gb} / \mathrm{s}$ operation (a). Sensitivity evolution during cascade measurements (b)

As mentioned before, these regenerators are firstly performant wavelength converters. Other regenerator schemes have been proposed without wavelength conversion. Loss-free $3 \mathrm{R}$ regeneration has been realized thanks to synchronous modulation in an SOA-MZI [8]: an error-free transmission over 10,000km with $2^{23}-1$ PRBS sequence has been obtained. SOA-MZI used in pass-through mode [9] and MMI-SOA's (Multimode interferometer-SOA's) [10] are other structures proposed for $2 \mathrm{R}$ regeneration, without cascade demonstration yet.

Anyway, in numerous cases the high bit rate operation is based on the definition of switching windows, thanks to different combinations of differential mode and short pulses width, masking the possible too slow response of the SOA's. As the SOA-MZI can present at least three independent inputs in the interferometer, the differential mode can be directly used to realize high bit rate functions like demultiplexing or add\&drop : for example, error free $336 \mathrm{~Gb} / \mathrm{s}$ toward $10.5 \mathrm{GHz}$ all-optical demultiplexing has been successfully demonstrated with an hybrid integrated symmetric SOA-MZI [11]. Without differential mode, logic functions like the XOR function can be realized by injecting separately both data streams to be compared in each branch of the MZI: both streams are converted on the same probe, as shown at $20 \mathrm{~Gb} / \mathrm{s}[12]$.

\section{SOA-based integrated interferometers: technologies suitable for real optical systems}

Among the XPM based devices mentioned above, the SOA-MZI is particularly attractive for optical processing thanks to its functionality and its integrability. It has been extensively studied in different integration schemes including hybrid MZI [13,14], active-passive MZI [15,16] and all-active device [17]. Anyway, its insertion in real systems will be successful only if several characteristics are simultaneously obtained : reduced cost (short fabrication time, high reproducibility and low power consumption during operation) ; compactness ; stability ; speed (operation at least at $40 \mathrm{~Gb} / \mathrm{s}$ ) ; use simplicity (by avoiding the differential mode and by limiting the tunable SOA number) ; tolerance to input signal fluctuations (high input power dynamic range (IPDR) and low polarization dependence) ; quality of the output signal. The hybridization concept as used for PLC (planar lightwave circuit) is particularly attractive due to its capability to integrate different functions on the same platform, and so to achieve very compact sub-systems. Up to now, such a SOA-MZI [13] has shown $10 \mathrm{~Gb} / \mathrm{s}$ low consuming wavelength conversion and $40 \mathrm{~Gb} / \mathrm{s}$ wavelength conversion in differential mode [14]. Anyway, it requires a quite complicated technological process whose risk increases with the number of functions to be integrated. In opposition, monolithically integrated all-active devices are fabricated with the simple and reproducible technological process of the standard SOA [17]. Thanks to the input signal SOA's, an IPDR higher than $15 \mathrm{~dB}$ [17] has been shown at 10 $\mathrm{Gb} / \mathrm{s}$ and good performance at $40 \mathrm{~Gb} / \mathrm{s}$ in differential mode [18]. Anyway the price of the technological simplicity is the use complexity due to the differential mode and to the tuning of at least two "not functional" input SOA's. Up to now, monolithically integrated active-passive devices with a butt-joint based technology have been also extensively fabricated, following different schemes (butt-joint with buried passive waveguide [15], butt-joint with deep ridge passive waveguides [16]), with up to $40 \mathrm{~Gb} / \mathrm{s}$ wavelength conversion, exclusively in differential mode [15]. Anyway, the fabrication of butt-joint based devices is a long and difficult process including at least three epitaxial steps [16] with finally similar performance as the all-active device.

For these reasons, a new active-passive device has been recently fabricated, associating the realization simplicity and the high IPDR of the all-active one, with the active-passive device operation simplicity added to the standard mode operation simplicity at $40 \mathrm{~Gb} / \mathrm{s}$ : thanks to an evanescent coupling between the active and the passive waveguides, the 4-SOA's MZI (Figure 2) has been realized with the single SOA technology. A long and highly confined conversion SOA design has been chosen to shorten the response time and achieve $40 \mathrm{~Gb} / \mathrm{s}$ standard mode operation on the C-band [19]: a low penalty and floor free BER has been simultaneously measured on the 4 tributaries (obtained after demultiplexing), as well as an 8dB IPDR by controlling the input SOA current. This 
device belongs at the same time to a new component generation, flexible and modular, and to a mature technology, simple and reproducible. It is particularly promising for high bit rate future all-optical $3 \mathrm{R}$ regenerators.
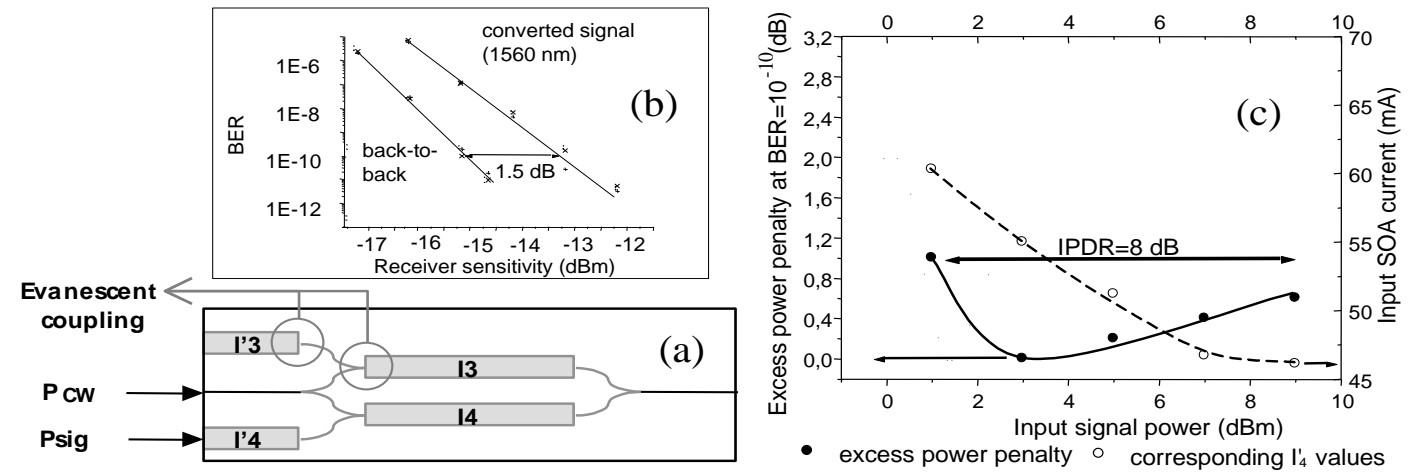

Fig. 2. (a) Scheme of the active-passive 4-SOA's evanescent coupling MZI. (b) Standard mode 40 Gb/s wavelength conversion on the four tributaries. (c) IPDR at $40 \mathrm{~Gb} / \mathrm{s}$ and corresponding control current.

\section{Conclusion}

Among SOA based devices for optical processing, XPM based interferometers are particularly attractive due to their functionality on one hand and their regenerative properties on the other hand. Different technological approaches have been presented to evaluate their suitability for insertion in system : while the hybrid integration presents the main advantage to allow integration of diversified functions for subsystem implementation, monolithically integrated active-passive evanescent coupling SOA-MZI assembles the interests of the technology simplicity and maturity, the design modularity and the use simplicity including standard mode $40 \mathrm{~Gb} / \mathrm{s}$ operation.

\section{References}

[1] A. E. Kelly, OFC'01, Anaheim, MB1

[2] K.E. Stubkjaer, IEEE J. Select.Topics Quantum Electron., Vol.6, No.6, pp.1428-1435, Nov./Dec. 2000

[3] A. D. Ellis et al, Electron. Lett., Vol.34, No20, pp1958-1959, Oct. 1998

[4] H.J. Thiele et al, Electron. Lett., Vol. 35, No3, pp230-231, Feb.1999

[5] Y. Ueno et al, IEEE Photon. Technol. Lett., Vol.13, No5, pp469-471, May 2001

[6] J. Leuthold et al, IEEE Photon. Technol. Lett., Vol.13, No8, pp860-862, Aug. 2001

[7] B. Lavigne et al, ECOC'01, Amsterdam, We.F.2.6

[8] O. Leclerc et al, OFC'01, Anaheim, WF6

[9] D. Wolfson et al, OFC'99, San Diego, PD36

[10] M. L. Nielsen et al, OFC'02, Anaheim, TuN2

[11] S. Nakamura et al, OFC'02, Anaheim, FD3

[12] T. Fjelde et al, Electr. Lett., Vol. 36, N²2, 26 Oct. 2000, pp $1863-1864$

[13] R. Sato et al, ECOC'01, Amsterdam, Th.F.2.3

[14] G. Maxwell et al, ECOC'02, Copenhagen, PD3.5

[15] M. Dulk et al, CLEO 2000, Nice, pp 276 -277

[16] A. Labrousse et al, OAA'01, Stresa, OWA2

[17] C. Janz et al, Elec. Lett., Vol.35, No7, pp 588-590, Apr.1999

[18] D. Wolfson et al, APCC/OECC'99, Beijing, pp 456-457

[19] B. Dagens et al , ECOC'02, Copenhagen, PD3.1 